\title{
Recent progress in the development of full color SrS-based electroluminescent phosphors
}

\author{
C.J. Summers*, B.K. Wagner, W. Tong, W. Park, M. Chaichimansour, \\ Y.B. Xin
}

Phosphor Technology Center of Excellence, School of Materials Science \& Engineering, Georgia Institute of Technology, Atlanta, GA 30332, USA

\begin{abstract}
A review is given of recent studies on SrS-based phosphors that are being developed for improving the color properties of electroluminescent (EL) displays. A dramatic improvement in the crystallinity, photoluminescence and EL performance for $\mathrm{SrS}: \mathrm{Cu}$ was achieved by vacuum annealing under a sulfur flow. The two-component $\mathrm{SrS}: \mathrm{Cu}, \mathrm{Ag}$ phosphor has been shown to exhibit an efficient blue color, thus combining the superior excitation properties of $\mathrm{Cu}$ with the strong blue radiative properties of $\mathrm{Ag}$. Additionally, studies in improving the EL efficiency by enhancing grain growth and by co-doping are discussed in a new green phosphor, $\mathrm{SrS}: \mathrm{Mn}$, and a preliminary results are presented for $\mathrm{SrS}: \mathrm{Eu}$. (C) 2000 Elsevier Science B.V. All rights reserved.
\end{abstract}

PACS: 78.60.Fi; 61.72.Vv; 78.55.Et

Keywords: Electroluminescence; SrS; Photoluminescence

\section{Introduction}

During the past few years significant progress has been made in enhancing the performance of electroluminescent (EL) displays and they are being actively considered for applications in head-mounted and automotive displays. It is expected that full color capability will shortly be available for headmounted applications, such as active matrix EL displays, and in $\frac{1}{4}$ VGA direct view panels, and with significantly higher brightnesses and lower power

\footnotetext{
* Corresponding author. Tel.: + 1-404-894-1260; fax: + 1404-894-1258.

E-mail address: chris@ptcoe.marc.gatech.edu (C.J. Summers).
}

consumption than current monochrome displays. Many of these advances are a result of recent progress made in EL phosphor technologies.

The development of an optimized EL phosphor is dependent on many variables. Of critical importance is the interaction between the rare earth or transition metal ion activators and the host lattice. This interaction determines the color and luminance of the device. Of secondary consideration for rare earths is the choice of co-activators for charge compensation so as to minimize traps and non-radiative losses. Further considerations can involve substitutional alloying which, by reducing the crystal symmetry and changing the ligand field coupling to the activator, can be used to enhance the luminance and fine tune the chromaticity. 
The crystalline quality of the thin films also is critical to maximize the luminance output. Ideally, films with columnar grains up to $\sim 2 \mu \mathrm{m}$ in size are required in these films, which are typically $0.5-1.0 \mu \mathrm{m}$ thick. This allows efficient excitation of the "hot" electrons and provides internal interfaces to minimize light piping along the film. All of these properties have to be obtained in a single film and ideally grown at low-temperatures so that lowtemperature substrates and processes can be utilized. We describe below the progress being made to develop more optimized full color SrS-based EL phosphors.

\section{New developments in electroluminescent phosphors}

$\mathrm{SrS}: \mathrm{Cu}$ was first reported as a potential blue electroluminescent (EL) emitter by Kane et al. in 1985 [1]. Recently, Sun et al. prepared SrS : Cu EL devices using magnetron sputtering followed by a $810^{\circ} \mathrm{C}$ anneal with a significant improvement in $60 \mathrm{~Hz}$ luminance at $40 \mathrm{~V}$ above the threshold to $L_{40}=28 \mathrm{~cd} / \mathrm{m}^{2}$ with $1931 \mathrm{CIE}$ color coordinates of $x=0.15, y=0.23$ [2]. The emission of $\mathrm{Cu}^{+}$centers in alkaline-earth sulfides was identified as a $3 \mathrm{~d}^{9} 4 \mathrm{~s}$ $\left({ }^{3} \mathrm{E}\right) \rightarrow 3 \mathrm{~d}^{10}\left({ }^{1} \mathrm{~A}_{1}\right)$ intra-ionic transition [3]. The broad emission resulted in significant emission intensity with y-chromaticity below 0.15 for a more saturated blue color compared to $\mathrm{SrS}: \mathrm{Ce}$. Their study showed that $\mathrm{SrS}: \mathrm{Cu}$ was superior to $\mathrm{SrS}: \mathrm{Ce}$ for the color-by-white approach to full color EL displays. However, a further two-fold increase in EL luminous efficiency is needed for a bright $\frac{1}{4}$ VGA display. Also, a low-temperature process $\left(\leq 650^{\circ} \mathrm{C}\right)$ is needed so that low-temperature glass substrates can be used to reduce production costs.

\subsection{Growth and in situ annealing of $\mathrm{Sr} S \mathrm{Cu}$}

For the molecular-beam epitaxy (MBE) growth of $\mathrm{SrS}: \mathrm{Cu}$ a methodology previously used to improve the EL performance of $\mathrm{SrS}$ : Ce was used [4]. However, whereas $\mathrm{Ag}^{+}$was used to compensate $\mathrm{Ce}^{3+}$ doping in $\mathrm{SrS}$ and reduce the induced $\mathrm{Sr}$ vacancy concentration [5], a series of codoping studies using trivalent ions to substitute on the $\mathrm{Sr}$-site and/or $\mathrm{Cl}$ doping on the $\mathrm{S}$-site were investigated to compensate the substitution of $\mathrm{Sr}^{2+}$ with $\mathrm{Cu}^{+}$and to reduce the charge imbalance induced $S$ vacancies. In addition, other material processes were studied to directly reduce sulfur vacancies.

The $\mathrm{SrS}: \mathrm{Cu}$ thin films were deposited on glass/ITO/ATO substrates at a rate of $0.1-0.2 \mu \mathrm{m} / \mathrm{h}$ to thicknesses of between 0.3 and $0.6 \mu \mathrm{m} . \mathrm{SrS}: \mathrm{Cu}$ was initially grown under high $\mathrm{S} / \mathrm{Sr}$ ratios as determined from previous $\mathrm{SrS}$ : Ce studies [4] at growth temperatures from $500^{\circ} \mathrm{C}$ to $700^{\circ} \mathrm{C}$. The elemental $\mathrm{Cu}$ and other solid source materials such as $\mathrm{Mn}$, $\mathrm{YCl}_{3}$, and $\mathrm{Ag}$ were thermally evaporated for the co-doping studies. The $\mathrm{Cu}$ flux was varied from $1 \times 10^{-8}$ to $1 \times 10^{-6}$ Torr [6]. However, in contrast to the $\mathrm{SrS}: \mathrm{Ce}$ results, these conditions produced films with a dark brown body color and weak luminescence. Strong photoluminescence (PL) was only observed for samples grown at $700^{\circ} \mathrm{C}$ but these samples exhibited weak EL emission. Studies using excess $\mathrm{S}$ and $\mathrm{Mn}, \mathrm{Al}, \mathrm{YCl}_{3}$, and $\mathrm{Ag}$ were also conducted, but resulted in little improvement.

A systematic study of post-deposition, in situ vacuum annealing under a sulfur flux was therefore carried out to reduce the native defect density. This was found to dramatically improve both the sample morphology and the EL and PL intensity. Fig. 1 shows the PL intensity versus annealing time for various anneal temperatures and sulfur flow rates. All samples were grown under the same growth conditions at $600^{\circ} \mathrm{C}$ and annealed for 30 min at $650^{\circ} \mathrm{C}$ under a $2.5 \mathrm{sccm}\left(\mathrm{N}_{2}\right.$ equivalent $)$ t-butyl mercaptan (t-BuSH) flow. As shown, this led to a dramatic increase in the PL intensity by a factor of almost 35, which was attributed to a reduction of sulfur vacancies. For these studies, the best EL performance was obtained for a sample annealed for $60 \mathrm{~min}$ with $L_{40}=40 \mathrm{~cd} / \mathrm{m}^{2}(1 \mathrm{kHz})$ and CIE coordinates of $x=0.20, y=0.32$.

Low-temperature PL decay time measurements showed a similar trend, and for a $30 \mathrm{~min}$ anneal at $650^{\circ} \mathrm{C}$, the $10 \mathrm{~K}$ decay time increased from $<20$ to $140 \mu$ s indicating that non-radiative processes were greatly suppressed by annealing. Furthermore, charge deep level transient spectroscopy (QDLTS) studies also showed a reduction in the sulfur vacancy concentration [7], and after annealing, the 


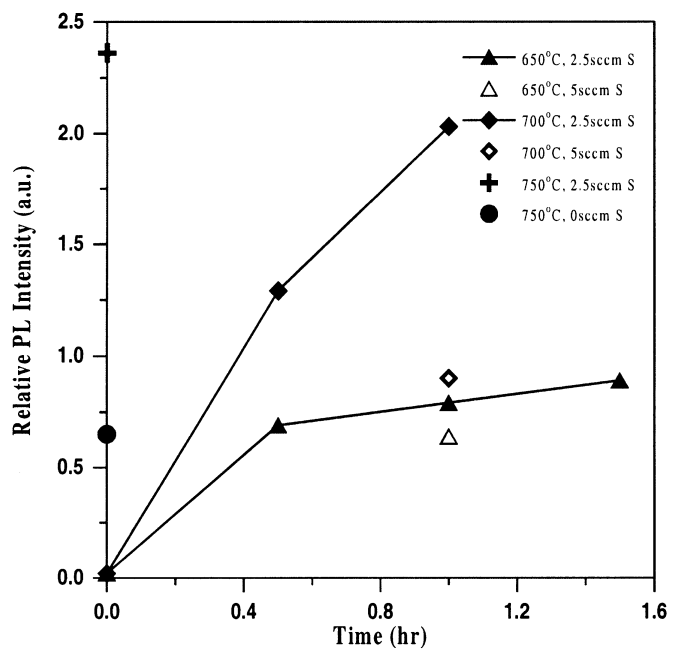

Fig. 1. Photoluminescence intensity of $\mathrm{SrS}: \mathrm{Cu}$ as a function of annealing time.

grain size increased from 0.4 to $1-2 \mu \mathrm{m}$, as shown in Fig. 2. The white areas in Fig. 2(a) have more than 5 times the $\mathrm{Cu}$ concentration of the nonwhite areas as measured by energy dispersive X-ray analysis. These results indicated that $\mathrm{Cu}$ precipitation occurs in the as-grown samples, but that annealing eliminated the $\mathrm{Cu}$ precipitation and greatly improved the grain size. X-ray diffraction studies also indicated at least twice the $\left(\begin{array}{lll}0 & 0 & 2\end{array}\right)$ peak intensity for annealed samples as compared with unannealed ones. This improvement in crystallinity and $\mathrm{Cu}$ doping uniformity greatly improved the EL performance. Through a further optimization of the growth conditions and by reducing the deposition temperature to $400^{\circ} \mathrm{C}$, a $60 \mathrm{~Hz}$ EL luminance of $L_{40}=26 \mathrm{~cd} / \mathrm{m}^{2}\left(400 \mathrm{~cd} / \mathrm{m}^{2}\right.$ at $\left.1 \mathrm{kHz}\right)$ with bluer CIE coordinates of $x=0.17, y=0.29$ was obtained.

\subsection{SrS: Mn thin film phosphors for green electroluminescence}

The progress made in developing more efficient blue EL phosphors has led to a need for improved green and red EL phosphors. At present, $\mathrm{ZnS}: \mathrm{Tb}$ is known to be the most efficient green EL material. However, its efficiency is 2-3 times less than the value ideally required for a bright VGA display. Therefore, the development of an efficient green EL phosphor becomes very important for realizing a full color flat panel display technology. SrS : Mn is a possible candidate as it has exhibited very bright green cathodoluminescence (CL) [8] and photoluminescence (PL) [9] with an excellent chromaticity. However, although not extensively investigated, the EL results reported on thin film $\mathrm{SrS}: \mathrm{Mn}$ are poor [10]. A study was, therefore, made on this phosphor using a similar methodology as described in Section 2.1.

Structural and optical characterizations for $\mathrm{SrS}: \mathrm{Mn}$ thin films grown on ATO/ITO/glass showed that the EL emission peaked at $540 \mathrm{~nm}$ with CIE coordinates of $x=0.33, y=0.64$ but that the grain size was very small $(\sim 0.3 \mu \mathrm{m})$. In contrast to the PL emission, the $60 \mathrm{~Hz}$ EL intensity was very weak with a $L_{40}$ of less than $4.2 \mathrm{~cd} / \mathrm{m}^{2}$. The large difference was attributed to the different
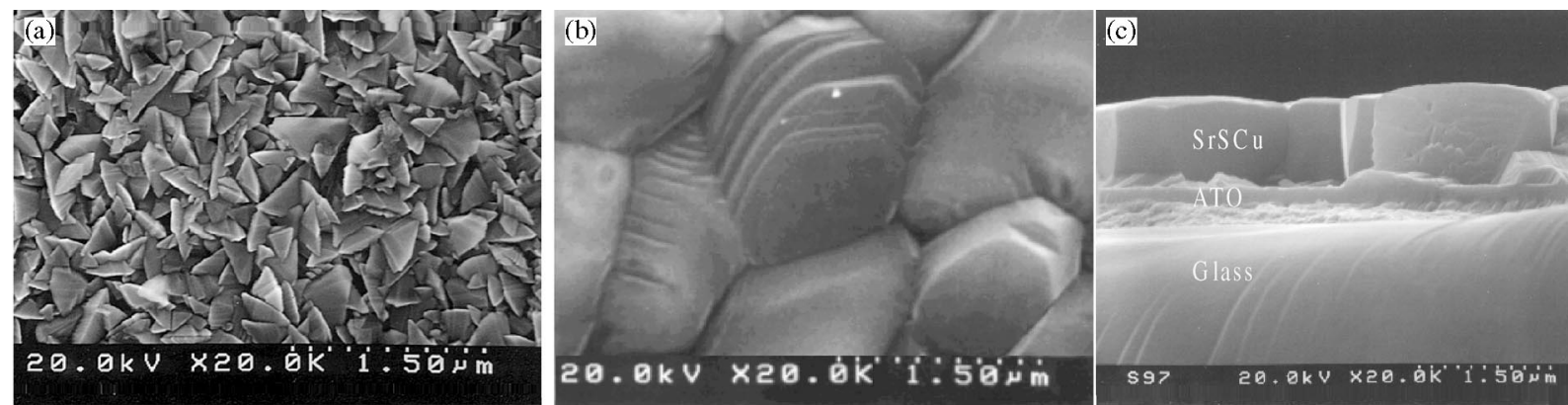

Fig. 2. SEM micrographs of $\mathrm{SrS}: \mathrm{Cu}$ thin films (a) as-grown, (b) vacuum annealed at $650^{\circ} \mathrm{C}$ under a t-BuSH flow of $2.5 \mathrm{sccm}$, and (c) a cross-sectional view of annealed $\mathrm{SrS}: \mathrm{Cu}$. 
excitation mechanisms of PL and EL. In EL devices, "hot" electrons excite the activators and ideally grain sizes greater than $0.5 \mu \mathrm{m}$ are needed to accelerate the electrons to high enough energy, otherwise they are scattered at the grain boundaries [6]. Because the impact cross section of $\mathrm{Mn}^{2+}$ in $\mathrm{SrS}$ is much smaller than in $\mathrm{ZnS}$ [11], a higher concentration of "hot" electrons are needed to excite the same number of $\mathrm{Mn}^{2+}$ ions in SrS. Therefore, the poor EL performance of $\mathrm{SrS}: \mathrm{Mn}$ was attributed to the small grain size.

However, in the study of the MBE growth of $\mathrm{SrS}: \mathrm{Cu}$ described in Section 2.1, it was found that a large grain size $(1-2 \mu \mathrm{m})$ could easily be obtained after an in situ post growth annealing [6]. Fig. 3 shows the dependence of grain size on $\mathrm{Cu}$ flux showing that $\mathrm{Cu}$ is a good nucleation agent to promote grain growth in $\mathrm{SrS}$ with a maximum grain size of $1.8 \mu \mathrm{m}$ being achieved. Therefore, a series of $\mathrm{SrS}: \mathrm{Mn}, \mathrm{Cu}$ samples were grown for $\mathrm{Mn}$ fluxes between $3 \times 10^{-9}$ and $1.2 \times 10^{-7}$ Torr in combination with the optimum $\mathrm{Cu}$ flux determined from this study. Fig. 3(b) shows that, unfortunately, the grain size decreased quickly with increasing Mn flux because of a pinning effect. For $F_{\mathrm{Mn}}=$ $1.2 \times 10^{-7}$ Torr, which is close to the optimum $\mathrm{Mn}$ flux for pure $\mathrm{SrS}: \mathrm{Mn}$, the average grain size decreased to $0.5 \mu \mathrm{m}$, compared to $0.3 \mu \mathrm{m}$ grains for the SrS:Mn samples. The surface morphologies also changed due to the addition of Mn. There are many small particles at the grain boundaries, and the grain boundary structure shows more curvature compared with that of pure $\mathrm{SrS}: \mathrm{Cu}$ (Fig. 3 inset). The concentration of small particles also increased with the Mn flux and therefore were identified as being associated with $\mathrm{Mn}^{2+}$ and also responsible for pinning the grain size. The $\mathrm{Mn}$ pinning effect is well understood in the field of metallurgy and is used to obtain fine-grain alloys $[12,13]$. It was shown that second phase particles on the grain boundary play the major role in this effect [14]. In the case of $\mathrm{SrS}: \mathrm{Mn}, \mathrm{Cu}, \mathrm{Mn}^{2+}$ has a smaller ionic radius $(0.8 \AA)$ than $\mathrm{Sr}^{2+}(1.13 \AA)$ and a higher surface mobility [4]. It can therefore easily migrate to the grain boundaries during growth and form second phase particles. These particles reduce the grain boundary area and lower the driving force for grain growth. EL devices were fabricated and
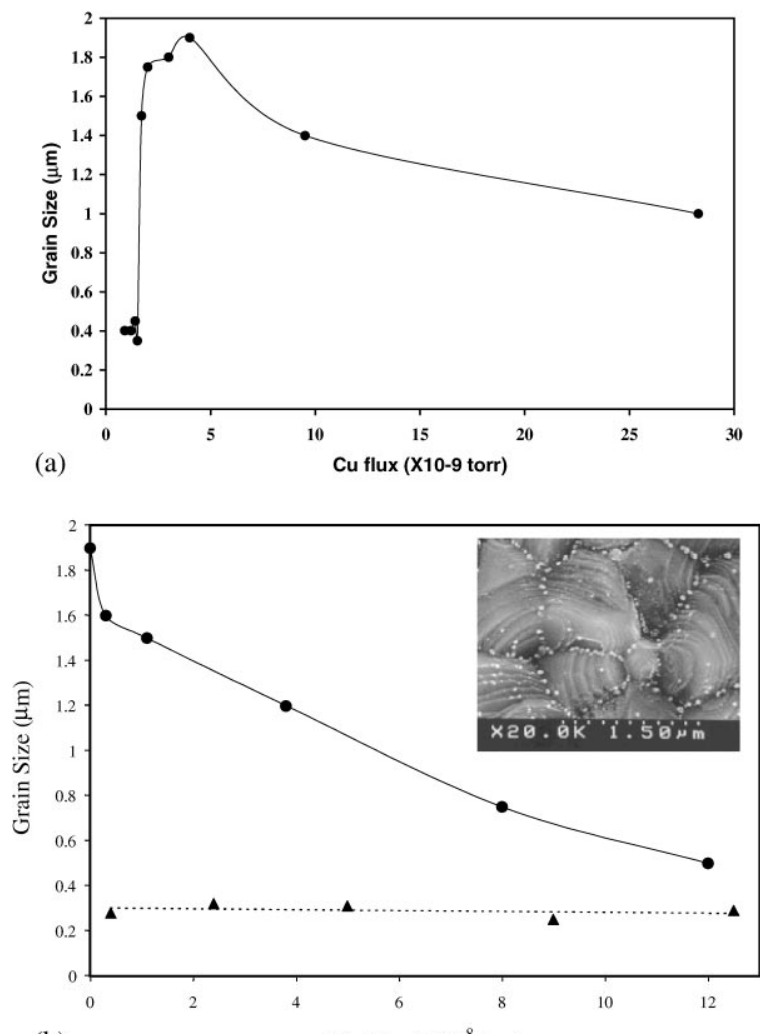

(b)

Mn Flux (x10-8 torr)

Fig. 3. Grain size as a function of $\mathrm{Cu}$ flux for thin film $\mathrm{SrS}: \mathrm{Cu}$, and (b) as a function of $\mathrm{Mn}$ flux in thin films of $\mathrm{SrS}: \mathrm{Mn}, \mathrm{Cu}(\mathbf{O})$ and $\mathrm{SrS}: \mathrm{Mn}(\boldsymbol{\Delta})$. (Inset: Morphology of a $\mathrm{SrS}: \mathrm{Mn}, \mathrm{Cu}$ sample).

measured for $\mathrm{SrS}: \mathrm{Mn}, \mathrm{Cu}$ samples with the optimum $F_{\mathrm{Cu}}$ as a function of Mn flux. The $\mathrm{Mn}^{2+}$ green EL emission dominated for $F_{\mathrm{Mn}} \geq 1.1 \times 10^{-8}$ Torr. For $F_{\mathrm{Mn}}=1.1 \times 10^{-8}$ Torr, the $60 \mathrm{~Hz} L_{40}$ was $5.4 \mathrm{~cd} / \mathrm{m}^{2}$ with CIE coordinates of $x=0.31$, $y=0.53$, compared to no detectable EL for $\mathrm{SrS}$ : Mn samples with the same growth and annealing conditions. The increase in brightness is attributed to the larger grain size compared with that for the pure $\mathrm{SrS}$ : Mn sample. The $\mathrm{Mn}^{2+}$ emission intensity did not increase significantly with increasing Mn flux, possibly because the increased concentration of $\mathrm{Mn}^{2+}$ activators was offset by the reduced the grain size due to the Mn pinning effect. However, a greatly improved $60 \mathrm{~Hz}$ EL performance of $L_{40}=71 \mathrm{~cd} / \mathrm{m}^{2}$ with an efficiency $\left(\eta_{40}\right)$ 
of $0.43 \mathrm{~lm} / \mathrm{W}$, was obtained for a $400^{\circ} \mathrm{C}$ deposition and a post-deposition in situ vacuum anneal similar to that used for the $\mathrm{SrS}: \mathrm{Cu}$ process.

\subsection{Growth and characterization of $\mathrm{SrS}: \mathrm{Cu}, \mathrm{Ag}$}

As a result of the breakthrough in obtaining efficient EL emission with a good blue chromaticity from $\mathrm{SrS}: \mathrm{Cu}[2,3,15]$, attention was directed to a similar system, $\mathrm{SrS}: \mathrm{Ag}$, which exhibits a highly saturated blue PL and cathodoluminescence emission centered at $430 \mathrm{~nm}$. However, the EL intensity was found to be very weak [16] which was attributed to poor EL excitation efficiency. Therefore, attempts were made to improve the EL performance of $\mathrm{SrS}: \mathrm{Ag}$ by co-doping with $\mathrm{Cu}$. In this two-component system, the high excitation efficiency of $\mathrm{Cu}$ and the high luminescence efficiency of $\mathrm{Ag}$ are combined to produce highly efficient EL with superior blue chromaticity. The use of two different types of ions for high excitation efficiency and desirable color adds great flexibility to phosphor development. However, the successful sensitization depends critically on efficient coupling between the $\mathrm{Cu}$ sensitizer and the $\mathrm{Ag}$ activator. The luminescence characteristics of $\mathrm{SrS}: \mathrm{Cu}, \mathrm{Ag}$ were, therefore, investigated to precisely probe the interaction between the $\mathrm{Cu}$ and $\mathrm{Ag}$ ions to ascertain the efficiency of the coupling between the two ions [17].

As shown in Fig. 4, $\mathrm{SrS}: \mathrm{Cu}, \mathrm{Ag}$ exhibits a deep blue color at $300 \mathrm{~K}$ with a peak emission at $2.876 \mathrm{eV}(430 \mathrm{~nm})$ and a line width of $390 \mathrm{meV}$, providing a highly saturated blue CIE color coordinates of $x=0.165, y=0.088$. As the temperature was decreased to $10 \mathrm{~K}$, the emission band did not shift and two additional emission bands were observed at 3.443 and $2.398 \mathrm{eV}$. Comparisons with the low-temperature PL spectra of singly doped $\mathrm{SrS}: \mathrm{Cu}$ and $\mathrm{SrS}: \mathrm{Ag}$ showed that the two peaks at 3.443 and $2.876 \mathrm{eV}$ were emissions from $\mathrm{Ag}$ and the $2.398 \mathrm{eV}$ peak was emission from $\mathrm{Cu}$. This assignment was also supported by the temperature dependence of these emission bands in singly doped $\mathrm{SrS}: \mathrm{Ag}$ and $\mathrm{SrS}$ : $\mathrm{Cu}$ samples; the two Ag emission bands were independent of temperature whereas the $\mathrm{Cu}$ emission exhibited a large blue shift with increasing temperature [18].

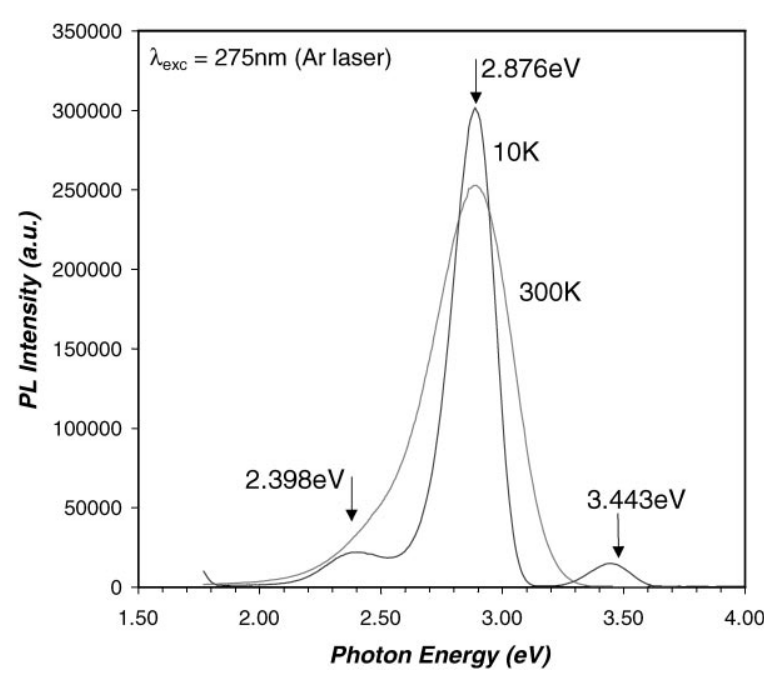

Fig. 4. Photoluminescence spectra of a $\mathrm{SrS}: \mathrm{Cu}, \mathrm{Ag}$ thin film at 10 and $300 \mathrm{~K}$.

Similar PL properties were also found for various $\mathrm{Ag}$ concentrations with a fixed $\mathrm{Cu}$ concentration. Fig. 5 shows the main emission peak position and PL intensity as a function of the concentration ratio, $\mathrm{Ag} /(\mathrm{Cu}+\mathrm{Ag})$. It is clear that the main emission band shifts from the $\mathrm{Cu}$ emission band to the Ag emission band when the concentration ratio exceeds 0.44. The Ag emission intensity also increased with increasing $\mathrm{Ag} /(\mathrm{Ag}+\mathrm{Cu})$ concentration ratio and at a ratio of 0.62 exhibited a five-fold enhancement compared to singly doped $\mathrm{SrS}: \mathrm{Ag}$, before decreasing at higher $\mathrm{Ag} /(\mathrm{Ag}+\mathrm{Cu})$ concentration ratios. On the other hand, the $\mathrm{Cu}$ emission intensity monotonically decreased as the $\mathrm{Ag} /(\mathrm{Ag}+\mathrm{Cu})$ concentration ratio was increased and at a concentration ratio of 0.62 it was reduced by a factor of 2, compared to the singly doped $\mathrm{SrS}: \mathrm{Cu}$. This enhancement of the $\mathrm{Ag}$ emission and the simultaneous suppression of the $\mathrm{Cu}$ emission in the $\mathrm{SrS}: \mathrm{Cu}, \mathrm{Ag}$ samples are indicative of energy transfer from $\mathrm{Cu}$ to $\mathrm{Ag}$. In further support of the energy transfer model, the photoluminescence excitation (PLE) measurements showed that the $\mathrm{Cu}$ excitation bands appeared in the excitation spectra of the Ag emission band, directly confirming energy transfer between the $\mathrm{Cu}$ and $\mathrm{Ag}$ ions [19]. 


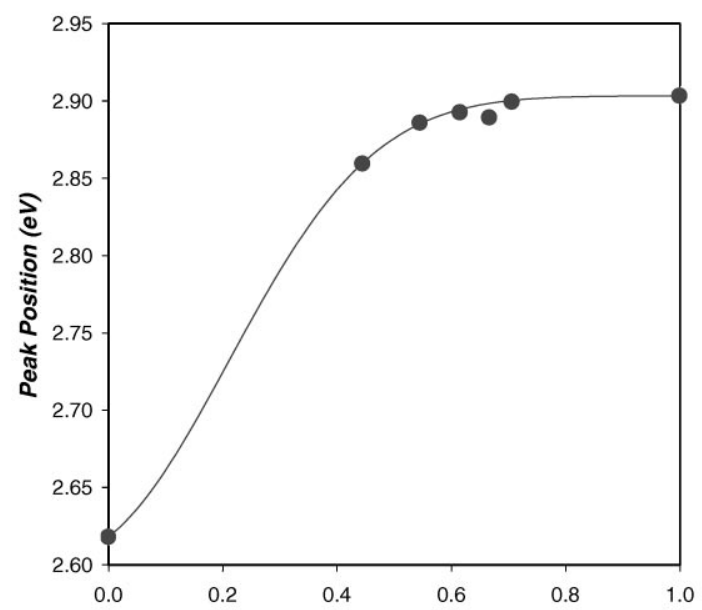

(a)

$\mathrm{Ag} /(\mathrm{Ag}+\mathrm{Cu})$ Concentration Ratio

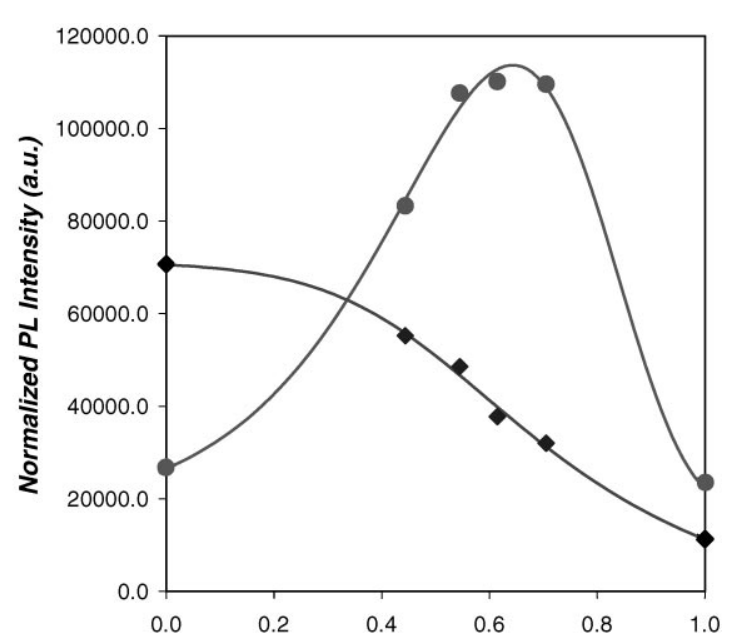

(b)

$\mathrm{Ag} /(\mathrm{Ag}+\mathrm{Cu})$ Concentration Ratio

Fig. 5. (a) The main emission peak position as a function of $\mathrm{Ag} /(\mathrm{Ag}+\mathrm{Cu})$ concentration ratio. (b) The PL intensity of the $2.876 \mathrm{eV} \mathrm{Ag}$ emission $(-)$ and the $2.398 \mathrm{eV} \mathrm{Cu}$ emission bands $(\bullet)$ as a function of $\mathrm{Ag} /(\mathrm{Ag}+\mathrm{Cu})$ concentration ratio. The excitation wavelength was $275 \mathrm{~nm}$.

EL characterizations were also consistent with the PL study and it was evident that the emission from $\mathrm{SrS}: \mathrm{Cu}, \mathrm{Ag}$ originated from the same center as the singly-doped Ag system. Typical $60 \mathrm{~Hz}$ EL results for sputtered $\mathrm{SrS}: \mathrm{Cu}$ were $L_{40}=34 \mathrm{~cd} / \mathrm{m}^{2}$ at $x=0.16, y=0.24$ and $\eta_{40}=0.25 \mathrm{~lm} / \mathrm{W}$, and for sputtered $\mathrm{SrS}: \mathrm{Ag}, L_{40}=0.3 \mathrm{~cd} / \mathrm{m}^{2}$ at $x=0.17$, $y=0.16$ with $\eta_{40}=0.001 \mathrm{~lm} / \mathrm{W}$, whereas sputtered $\mathrm{SrS}: \mathrm{Cu}, \mathrm{Ag}$ yielded $L_{40}=27 \mathrm{~cd} / \mathrm{m}^{2}$ at $x=0.17$, $y=0.15$ and $\eta_{40}=0.25 \mathrm{~lm} / \mathrm{W}$. To gain greater insight into this sensitization mechanism, detailed electrical characterizations were performed [20]. It was found that $\mathrm{SrS}: \mathrm{Ag}$ exhibited nearly ideal capacitance $(\mathrm{C}-\mathrm{V})$ characteristics with no capacitance overshoot near the threshold voltage. From internal charge-phosphor field $\left(\mathrm{Q}-\mathrm{F}_{\mathrm{p}}\right)$ measurements, the total transferred charge at $40 \mathrm{~V}$ above threshold was evaluated to be $76 \mathrm{nC}$. Also, no trailing edge emission was observed in $\mathrm{SrS}: \mathrm{Ag}$ for voltages as high as $60 \mathrm{~V}$ above threshold. Thus, there is no localized space charge generation in the phosphor. However, contrasting behavior was observed from the singly doped $\mathrm{Cu}$ and $\mathrm{Cu}-\mathrm{Ag}$ codoped samples, as shown in Fig. 6. Both $\mathrm{SrS}: \mathrm{Cu}$ and $\mathrm{SrS}: \mathrm{Cu}, \mathrm{Ag}$ exhibited a large capacitance overshoot in their $\mathrm{C}-\mathrm{V}$ curves and the $Q_{\max }-V_{\max }$ curves yielded higher capacitances of 3.7 and $2.6 \mathrm{nF}$, respectively, in contrast to the measured insulator capacitances of $2.2 \mathrm{nF}$ for these devices. Both $\mathrm{SrS}: \mathrm{Cu}$ and $\mathrm{SrS}: \mathrm{Cu}, \mathrm{Ag}$ also exhibited a trailing edge emission which increased in magnitude with increasing applied voltage, indicating that the $\mathrm{Cu}$ centers were ionized. These factors indicated that space charge was generated by the ionization of $\mathrm{Cu}$ and then localized within the phosphor. Analysis shows that the space charge density, $N_{\mathrm{sc}}$, was $\sim 5.5 \times 10^{16} \mathrm{~cm}^{-3}$ in $\mathrm{SrS}: \mathrm{Cu}, \mathrm{Ag}$ which agrees very well with the values obtained for $\mathrm{SrS}: \mathrm{Cu}$ $\left(N_{\mathrm{sc}}=6.2 \times 10^{16} \mathrm{~cm}^{-3}\right)$. Due to the ionization of $\mathrm{Cu}$, the charge transferred in the singly $\mathrm{SrS}: \mathrm{Cu}$ and $\mathrm{SrS}: \mathrm{Cu}, \mathrm{Ag}$ samples (163 and $154 \mathrm{nC}$, respectively) was approximately twice that for the singly doped SrS:Ag $(76 \mathrm{nC})$. Since the space charge and the transferred charge were approximately the same for both the singly $\mathrm{Cu}$ doped and $\mathrm{Cu}-\mathrm{Ag}$ co-doped samples, the charge injection and transport properties were concluded to be independent of $\mathrm{Ag}$ doping and to be dominated by $\mathrm{Cu}$. However, the radiative (emission) characteristics were due to the $\mathrm{Ag}$ center, showing that energy transfer from $\mathrm{Cu}$ to $\mathrm{Ag}$ also occurred under $\mathrm{EL}$ excitation. 


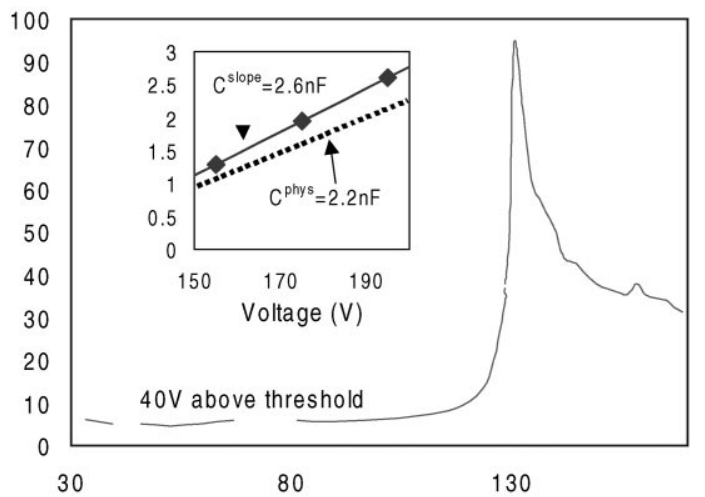

(a)

Voltage (V)

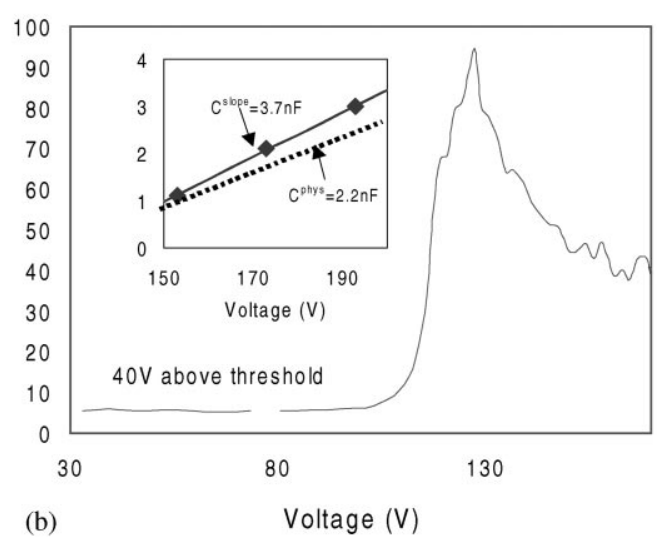

Fig. 6. $\mathrm{C}-\mathrm{V}$ and $Q_{\max }-V_{\max }$ curves for (a) $\mathrm{SrS}: \mathrm{Cu}, \mathrm{Ag}$ and (b) $\mathrm{SrS}: \mathrm{Cu}$.

From the above results, the excitation properties of $\mathrm{SrS}: \mathrm{Ag}, \mathrm{Cu}$ systems are dictated by the $\mathrm{Cu}$ centers, whereas the radiative properties are governed by the Ag centers. It is the energy transfer process which provides the bridge between $\mathrm{Cu}$ ions and the emitting ions. The conventional "single-component" phosphors are limited in that the activator must be efficient both in its excitation and radiative properties, restricting the number of efficient activators with the desired chromaticity for full color displays. However, these criteria can more easily be met for "two-component" phosphors. The activator should exhibit the desired color in the chosen host lattice and have a good radiative efficiency to maximize the luminescence. The sensitizer must have a large excitation cross-section to maximize the excitation efficiency. Of course, the success of this technique hinges on the strength of the energy transfer from the sensitizer to the activator ion. Successful sensitization of $\mathrm{SrS}: \mathrm{Cu}, \mathrm{Ag}$ opens up the possibility of designing and developing a new class of two-component EL phosphors that exhibit both superior color and excitation efficiency than conventional single-activator EL phosphors.

\subsection{SrS : Eu red EL phosphor}

Encouraged by the success of SrS systems for blue and green emission, studies were extended to

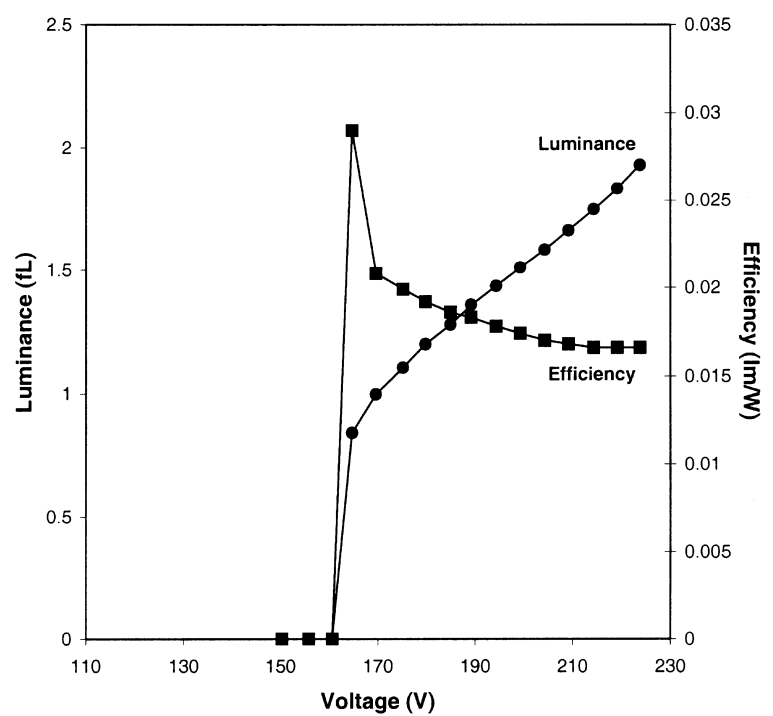

Fig. 7. SrS: Eu EL luminance and efficiency as a function of voltage.

obtain an efficient red phosphor. $\mathrm{SrS}: \mathrm{Eu}$ is a red emitting phosphor with an emission band centered at $610 \mathrm{~nm}$ giving CIE chromaticity coordinates of $x=0.600, y=0.395$. As Fig. 7 shows, however, the typical luminance and efficiency for this material are rather poor with $L_{40}=5 \mathrm{~cd} / \mathrm{m}^{2}$ and $\eta_{40}$ $=0.017 \mathrm{~lm} / \mathrm{W}$. 


\section{Summary}

A review has been given of new developments in SrS-based EL phosphors. It was demonstrated that a low-temperature $\left(650^{\circ} \mathrm{C}\right)$ sulfur anneal enhances the blue EL emission from MBE SrS: $\mathrm{Cu}$ phosphors. PL, decay time, QDLTS measurements and SEM studies indicated a great improvement in crystallinity, a large reduction in the sulfur vacancy concentration, and a large increase in the grain size due to the sulfur annealing process. The concept of a two-component phosphor has been introduced in which the superior excitation properties of a coactivator $(\mathrm{Cu})$ have been coupled to the desired radiative properties of the activator $(\mathrm{Ag})$. The strong energy transfer that occurs between these two ions has resulted in a new blue phosphor that significantly enhanced the color coordinates of EL displays. The success of the two-component phosphor approach opens a new pathway to the development of highly efficient EL phosphors with saturated color chromaticity. It has also been demonstrated that $\mathrm{Cu}$ can produce significant grain growth in SrS. However, in the development of a SrS-based green phosphor, a Mn pinning effect was observed which restricted the grain size to less than $0.5 \mu \mathrm{m}$ and which limited the EL performance. Traditional growth and process methods were not effective in overcoming the pinning problems, and thus, new techniques are needed to improve the brightness and efficiency of Mn-activated SrS EL phosphors. The potential of applying these techniques to other SrS-based phosphors is expected to result in a full color RGB set.

\section{Acknowledgements}

The authors wish to thank Dr. H. Menkara, Dr. T.C. Jones, and E. Mohammed for their contribution to this review. This work was supported by the Phosphor Technology Center of Excellence under DARPA Grant MDA972-93-1-0030.

\section{References}

[1] J. Kane, W. Harty, M. Ling, P. N. Yocom, SID '85 Digest, SID, Santa Ana, 1985, p. 163.

[2] S.-S. Sun, E. Dickey, J. Kane, P. N. Yocom, SID'97 Conference Record, SID, Santa Ana, 1997, p. 301.

[3] W. Park, T.C. Jones, W. Tong, B.K. Wagner, C.J. Summers, S.-S. Sun, Proceedings of the Third International Conference on Science and Technology of Display Phosphors, Huntington Beach, CA, November 3-5, 1997.

[4] W. Tong, L. Zhang, M. Chaichimansour, B.K. Wagner, C.J. Summers, SID'97 Conference Record, SID, Santa Ana, 1997, p. 305.

[5] W. Tong, L. Zhang, W. Park, M. Chaichimansour, B.K. Wagner, C.J. Summers, Appl. Phys. Lett. 71 (1997) 2268.

[6] W. Tong, Y.B. Xin, W. Park, C.J. Summers, Appl. Phys. Lett. 74 (1999) 1379.

[7] S.H. Sohn, Y. Hamakawa, Jpn. J. Appl. Phys. 31 (1992) 3901.

[8] B.T. Collins, M. Ling, J. Electrochem. Soc. 143 (1996) 2328.

[9] I. Matsuyama, N. Yamashita, K. Nakamura, J. Phys. Soc. Jpn. 58 (1989) 741.

[10] P. Soininen, M. Leskelä, L. Niinistö, E. Nykänen, E. Rauhala, In: Proceedings of the sixth Workshop on Electroluminescence, V.P. Singh, J.C. McClure (Eds.), Cinco Pluntos, El Paso, 1992, p. 217.

[11] B. Bringuier, K. Bhattacharyya, Semicond. Sci. Technol. $10(1995) 1065$.

[12] X. Xia, Scripta Metall. Mater. 28 (1993) 1213.

[13] M.J. Maloney, A.J. Garrratt-Reed, G.J. Yurek, Science and Technology of Rapidly Quenched Alloys Symposium, 1987, p. 261.

[14] B. Garbarz, F.B. Pickering, Mater. Sci. Technol. 4 (1988) 967.

[15] T.C. Jones, W. Park, E. Mohammed, B.K. Wagner, C.J. Summers, S.-S. Sun, in: Proceedings of the Materials Research Society Symposium, vol. 508, MRS, Pittsburgh, 1998, p. 281.

[16] S.-S. Sun, Fourth International Conference on the Science and Technology of Display Phosphors, Bend, OR, September, 14-17, 1998.

[17] W. Park, T.C. Jones, C.J. Summers, Appl. Phys. Lett. 74 (1999) 1785.

[18] W. Park, T.C. Jones, E. Mohamed, C.J. Summers, S.-S. Sun, Proceedings of the Fifth International Display Workshop, SID, Tokyo, 1998, p. 613.

[19] W. Park, T.C. Jones, C.J. Summers, International Conference on Luminescence, Osaka, Japan, August 23-27, 1999.

[20] T.C. Jones, W. Park, C.J. Summers, Appl. Phys. Lett. 75 (1999) 2398. 